\title{
LACK OF INFORMATION AND DIFFICULTY OF IMPLEMENTATION AS THE OBSTACLES TO THE ADOPTION OF PERFORMANCE MEASUREMENT SYSTEMS AT CZECH ORGANIZATIONS
}

\author{
Hana Gruntová Kolingerová
}

\begin{abstract}
The paper focuses on the topical issue of adopting standardized tools for the measurement of performance, with the centre of attention being a lack of information and the difficulty of implementation. The empirical part presents insights into the perception of the above aspects by selected Czech organizations. An analysis of data collected through a quantitative survey among 331 entities, carried out by the Institute for Evaluations and Social Analyses (INESAN) in 2012, indicates that the practice of performance measurement at organizations influences the perception of selected obstacles. Organizations that measure performance in selected areas and use selected procedures often claim they know which standardized tools are adequate for performance measurement, yet they also often perceive implementation as problematic. Conversely, the incidence of selected performance measurement issues at organizations is positively associated with the perception of both a lack of information and the perception of implementation as problematic.
\end{abstract}

\section{Key words}

Performance measurement, obstacles, lack of information, implementation, quantitative research, Czech organizations

\section{Introduction}

Performance measurement systems (PMS) have been increasingly implemented at organizations over the course of the recent decades. PMS are comprehensive approaches to the measurement and management of organizational performance. The most used standardized tools include Balanced Scorecard, Activity Based Costing/Management, Value-Based Management, and other methods using a set of Key Performance Indicators. The implementation of such a tool is a complex procedural activity involving a multitude of obstacles spanning from the moment of individual decision made by the organization's management team all the way to the full live deployment of the system. Obstacles, which can occur for various reasons and may cause an organization to eventually avoid adopting a performance measurement system, include perceived shortage of information and difficulty of implementation.

The goal of this paper is to show to what extent the management teams of selected Czech business organizations, which have not implemented standardized PMS yet, consider a lack of information and difficulty of implementation to be obstacles to the adoption of a standardized performance measurement system. This includes an insight into how this perception differs among organizations depending on whether they measure performance in selected areas, what performance measurement processes they use and what problems they encounter in performance measurement. The data that the conclusions of this paper rely on comes from a quantitative survey among 331 entities, carried out by the Institute for Evaluations and Social Analyses (INESAN) in 2012. 


\subsection{Problems with the acceptance of performance measurement systems}

Changes in the competitive environment and a pressure towards transparency at organizations in many areas have resulted in an interest in PMS. However, the acceptance, construction and implementation of such a tool represent a major issue and, although various organizations have been increasingly using these systems, their acceptance is often problematic (KeathleyHerring, 2017; De Waal a Kourtit, 2013). The following text focuses on the issues of information and implementation.

The demand for performance measurement tools goes hand in hand with their ongoing development, which has been increasingly associated with the development of information technology (Gimžauskienè and Varaniūte, 2012). This, however, entails increased requirements for organizations that may find it increasingly difficult to navigate the existing supply. One of the problems can be finding enough information, which is a crucial requirement for choosing an adequate tool. Obtaining information about available solutions is the principal content of the exploration and analysis undertaken following the decision to use a performance measurement system. This phase includes research into the available and adequate solutions and both internal and external analysis to provide insights into the characteristics of the organization (including the existing performance measurement method) and of the environment where the organization operates.

Exploration and analysis is followed by the adaptation or construction of the selected PMS, and then by the implementation phase whose quality informs the possibilities for using the tool. This involves the commissioning of the tool for the purpose of collecting, processing and reporting data, based on which it is possible to measure the organization's processes and assess the efficiency and effectiveness of operations, measures etc. According to some opinions, many of efforts geared towards the implementation of PMS fail and many organizations are incapable of implementing the system completely or efficiently (Keathley and Van Aken, 2013). According to de Waal and Counet (2009), this often causes rejection of such management techniques.

\subsection{Lack of information}

If an organization makes the decision to adopt a performance measurement tool, the first step to take is gaining enough information enabling it to make the decision on the choice of the adequate PMS. While there are a number of practically orientated publications and a wealth of online resources, Tangen (2004) notes that accessing information about PMS involves difficulties that cause organizations to struggle with a shortage of such information.

According to Tangen (2004), there is a major issue in ambiguous terminology of the field of expertise where concepts such as "productivity", "efficiency" and "performance" are often used without a clear notion what the terms actually mean. Tangen (2004) notes that this issue manifests both in practice and theory. According to Monkhouse (1995), it appears that any new management concept falls prey to incorrect interpretation.

Another problematic aspect according to Tangen (2004) is the huge quantity of existing PMS to choose from. There is a great amount of concepts for designing performance measurement (Tangen, 2004) as well as a great amount of various metrics (Paranjape et al., 2006). While the great number of various options for designing a unique PMS may appear to be a benefit, a great amount of options without a clear method for choosing from them causes uncertainty in practice (Tangen, 2004). Monkhouse notes (as early as in 1995) that some observers be- 
lieve that the business world is in danger of drowning in a sea of quantitative and qualitative measurements. According to Cavalluzzo and Ittner (2004), the principal obstacle to PMS innovation is the choice and interpretation of suitable performance metrics for activities that are difficult to measure by nature.

In effect, on the one hand there are many concepts and metrics, and on the other hand there are scarce practical guides to help with decisions on which measurement method is fitting for the specific needs of a specific organization. Hence, another issue is in the lack of manuals for designing a proprietary solution. PMS exhibit a great degree of variability across organizations, because the system must be correlated to the company's strategy (Roshan and Jenson, 2014)and the strategy is unique to each organization. This is associated with another issue observed by Tangen (2004), which is insufficient analysis of the organization's own environment, which should provide key performance indicators depending on the nature of the organization. At the same time, there is a huge amount of requirements arising from the complexity of PMS that practitioners want to meet (Tangen, 2004).

The increasing complexity and sophistication of approaches and the ongoing softwarisation of system may result in an increased importance of consulting and assistance services, which can guide organizations through the process of creating the tool. However, small enterprises in particular can face issues in terms of being unable to afford such services, and trust in such firms and their solutions may also be problematic. Tangen (2004) notes that the question of how to use the system has become confusing also because the proponents of a particular form of measurement tend to emphasize the benefits of their proposed approach, yet they are reluctant to discuss its issues or point out situations where the system may not be suitable.

While it appears that large corporations can benefit from the multitude of new metering techniques, how much these techniques are feasible for small and medium-sized enterprises remains a question. This is discussed for example in the case of the Balanced Scorecard (BSC). On the one hand, there are authors (Garengo et al., 2005) who consider this model unfit for small and medium-sized enterprises; on the other hand there are those who believe that the BSC can be an efficient tool for these entities too (see Basuony, 2014). For example, a BSCbased tool known as „Proved” a změř“ (Execute and Measure) was developed in the Czech Republic, and it is intended to provide an accessible solution involving minimum costs for small and medium-sized companies. It is a complete tool calibrated to the parameters of the companies whose owners, according to Srpová (Daňková, 2014), have no time to study documents describing the individual methods and procedures suitable for improving company performance.

\subsection{Problems with the implementation of PMS}

If an organization chooses a solution and successfully constructs or adapts it, it proceeds to implementing it, thereby completing the tool acceptance process. During implementation, it is interconnected with all involved areas and commissioned; this may also involve contesting the strategic assumptions (Wouters and Sportel, 2005). This is the most difficult part of the process of accepting a performance measurement system due to the scope of activities, which may affect the entire organization, so the issues of implementation are quite extensive.

As various authors confirm (see Bourne et al., 2003), implementation was of marginal interest to experts for a long time. Nevertheless, both literature and experience confirm that the process of implementation is not a simple matter manageable successfully within a short 
period of time as business conferences often tend to assert, according to Bourne at al. (2003) and that, often, not all measures, which are part of the envisaged operation of a standardized tool, are implemented.

Based on a review of literature published since 1996 and including predominantly scientific as well as certain relevant popular articles and books, De Waal and Counet (2009) list 31 problems that slow the implementation process down, make it incomplete or downright impossible. Based on these and other studies, problems can be categorized into five main groups that point to the individual key areas of implementation.

\section{(1) Management}

The importance of management culture, which plays a pivotal role throughout the process, has been brought up by many authors (Henri, 2006; Tangen, 2004; Basuony, 2014). According to them, certain organizations lack a performance management culture, manifesting in little emphasis on systematic performance management and generally weaker strategic planning (inadequate formulation and implementation of the strategy), which may stem from unfamiliarity with the strategic management techniques and processes. Beaver (2002) mention implementation issues where the sole proprietor/manager is very sensitive when it comes to business information and sharing strategic planning with employees.

Cavalluzzo and Ittner (2004) note the issue of the absence of management team involvement, which, according to Waal and Counet (2009), causes the other stakeholders working with the system to ascribe little importance to the activity. In other cases, the management team does not use performance information in day-to-day practice despite having it available. If the results do not improve the management of the organization may conclude that using a PMS yields no benefits and abandon the PMS. A change in the management team may also be a critical point, as a formerly accepted PMS is abandoned or gets low priority.

\section{(2) Resources}

Resources generally represent one of the principal problematic areas. A shortage of funding has been mentioned, though a lack of human resources is even more pressing (Fernandes et al., 2006; Todorov and Smallbone, 2014; Basuony, 2014). According to Chubb et al. (2011), improved professional competence of the employees directly influences the success of implementation. The problem with organizations is a shortage of systematic training and employee development in performance measurement techniques and a lack of knowledge and abilities in handling the PMS (Chubb et al., 2011, Cavalluzzo and Ittner, 2004).

Organizations may also find that more time and activity is needed than they initially expected and planned; a shortage of time for implementation makes the establishment of the tool in the organization problematic (de Waal and Counet, 2009). In their opinion the management team may be simply too busy with the day-to-day operation to pay sufficient attention to the implementation or it may be focused on satisfying stakeholder requirements while paying insufficient attention to internal management and control. Matters are also different when the organization is in an unstable phase (addressing major projects, restructuring, merger, or serious issues requiring increased involvement in governance etc.), as a result of which the attention paid to implementation is not sufficient.

\section{(3) Strategies, goals and definition of indicators}

Strategic planning and strategy operationalization are another issue. If the mission, strategy and goals are unclear and incomprehensible for the members of the organization, the critical 
success factors (CSF) and key performance indicators (KPI) developed for inclusion in the PMS will not be relevant for the organization. This involves individual problems such as difficulty in breaking the objectives down for the lower levels, difficulties in defining success factors and indicators (wrong or too many) or with linking them to a unit, team and individual responsibility. The nature of the organization can also play a role because, as Cavalluzzo and Ittner (2004) notes, the focus of the organization may require measuring indicators that are difficult to measure.

\section{(4) Attitude of the members of the organization}

Many authors (Fernandes et al., 2006; Chubb et al., 2011; Ulf et al., 2006) consider a positive attitude of managers and employees to the PMS to be one of the crucial issues. The attitude of stakeholders inside the organization needs to change to avoid a narrow focus on the implementation while ignoring the overall organizational change. If the goals of the implementation and the new system are not defined clearly and the understanding and acceptance of the PMS is lacking, disbelief and resistance will set in.

De Waal and Counet (2009) also believe that middle management and employees need to be motivated by education on their own benefits from using the PMS. Since the implementation of a PMS makes the performance of each worker more transparent, members of the organization may feel in danger and resist the PMS. Authors note that this issue occurs if the PMS is not sufficiently linked to the reward system - if the rewards are not governed by the output provided by the PMS.

\section{(5) Technological aspects of PMS}

Another issue is the technological standard and its implications. Limitations due to the inability of the existing information system to provide data in a valid, reliable, timely and costeffective way determine the use of performance information (Cavalluzzo and Ittner, 2004). According to Cavalluzzo and Ittner (2004) these technical issues play an even bigger role than cost. Furthermore, if the information and telecommunication system does not support the PMS sufficiently with automated collection, processing and reporting of key performance indicator data, which has to be done manually, the PMS is used in part only and can also be abandoned more easily.

According to de Waal and Counet (2009), other implementation issues occur if the system lacks cause-and-effect links or, by contrast, is too difficult in terms of causal links. The course and the result of the implementation is also affected if no employee is appointed to oversee the PMS or if the system is not updated regularly in response to changing conditions.

\subsection{Organizational readiness to PMS introducing and the approaches applied}

Some authors and practitioners are dedicated to designing a model of the preconditions necessary to introduce PMS, with emphasis on various aspects of organizational practices, e.g. employee buy-in, involvement in the process and proper communication of the change process (Ochurub, 2012), identifying stakeholders (de Lancer Julnes and Holzer, 2014), available human and material resources and time (Spearman, 2007), sufficient information (Tangen, 2004), defining strategy, (Eckerson, 2010), and linkages between the performance measures and the business unit's strategy (Hoque, 2014), and other.

There are a number of factors that have a negative impact on organizations' readiness for PMS implementation. This article points out the missing information and concerns regard- 
ing the implementation. An INESAN research (Gruntová Kolingerová, 2016) of 2012 showed that the acceptance of PMS in the Czech environment generally faces difficulties. A total of $49 \%$ of representatives of organizations considered funding requirements to be an obstacle to procuring a PMS, 30\% cited a lack of information for choosing an adequate solution and $29 \%$ mentioned concerns regarding the implementation. It was also shown that the perception of the two reviewed problems was related to whether or not the organizations had adopted a standardized tool for reviewing the degree of meeting its goals.

In organizations that had not adopted such a tool yet, $34 \%$ of representatives cited a lack of information as an obstacle and $24 \%$ of representatives cited difficulty of implementation. By contrast, in organizations where a tool had been adopted, $21 \%$ of representatives saw a lack of information as an obstacle whereas $38 \%$ representatives of the organizations cited the difficulty of implementation or its difficulty as an obstacle. Organizations that have not adopted a standardized tool yet perceive a lack of information more often while tending to underestimate the difficulty of implementation. Hence, the following analysis will focus on this type of entities, examining the connection between the perception of selected obstacles to the adoption of a standardized PMS with selected aspects of their practice.

But what impact does the practice of performance measurement (using non-standardized methods) have on certain factors of organizational readiness for introducing PMS? This issue is paid little attention, although it can be expected that the level of practice and the level of experience with performance measurement will affect whether or not an organization will accept standardized PMS. The experience includes the subject and procedures of performance measurement, and its issues.

The first includes various areas of organizational practices and indicators (Vincent and $\mathrm{Ku}$ mar, 2014; Muscalu and Şerban, 2014). The important areas in enterprises are finance, marketing, HRM or sale. Strategic evaluation is also highlighted (Bastian and Muchlish, 2012). Performance measurement procedures are individual steps of the performance management process, including strategy analysis, performance indicator identification, creation or adaptation of a performance measurement system, data collection (measurement) and interpretation, and application of performance measurement outputs, i.e. implementation of measures. Some authors (Lönnqvist, 2002; Marr, 2009) point out performance measurement issues that represent a wide spectrum of obstacles that organizations face within the entire performance management process.

\subsection{Research questions}

The research will generally focus on whether the perception of obstacles is related to the organizational experience with performance measurement. A lack of information and difficulty of implementation were chosen as obstacles. Three questions were asked for each obstacle:

(1) Are there differences in the perception of the obstacle between the representatives of the organizations depending on whether or not they monitor performance of the organization in selected areas of organizational activity?

(2) Does the perception of the obstacle differ between the representatives of the organizations depending on whether or not they use selected performance measurement procedures at the organization?

(3) Are there differences in the perception of the obstacle between the representatives of the organizations depending on the issues that they encounter at the organization in measuring performance? 
The selected areas of organizational activity are the corporate strategy, finance, HRM, sales and marketing; the selected performance measurement procedures are the reviewing the degree of meeting strategic objectives, ongoing monitoring of the results, obtaining information to rectify deviations from goals, comparing actual results with expectations or plans, and checking the achievement of the values of the individual indicator; and performance measurement issues include not knowing how to measure, insufficient analysis of business processes, lack of interest on the part of the management, unclear understanding of user expectations, low analytical abilities of in-house personnel, corporate culture not fostering performance measurement, insufficient cooperation between various department or teams, and a lack of data.

\section{Methodology}

The data analysed comes from the research conducted by INESAN as part of project CZ.3.01.2012.221.002 Performance Measurement Systems in Organizations, which focused on the systems, methods and approaches to performance measurement applied at Czech business organizations. As far as the selection of the review sample is concerned, the objectives of the research required selecting entities whose efforts related to performance measurement systems stemmed from their own initiative and were not imported from the headquarters of international corporations. Hence, the selection was made with emphasis on organizations in exclusively Czech ownership, i.e., without the declared presence of foreign capital. The ownership structure of the reviewed organizations was verified using the available registry of owners (RES, Business Register).

The selection set was obtained using a random selection technique; a total of 331 valid telephone interviews (CATI technique) were conducted with the leaders of various organizations (executives, CEO, CFO) on the territory of the Czech Republic in May 2012. A questionnaire that included both open-ended and closed-ended questions was used for the interviews. The response rate was $27 \%$. The analysis presented herein was only conducted using a group of organizations that have not deployed a standardized performance measurement tool to rate the degree of meeting their set objectives, i.e. with $66 \%$ of all organizations examined $(\mathrm{N}=217)$. Tables 1 to 3 show the identification data of the organizations. 


\begin{tabular}{l|c|c}
\hline Economic sector & $\begin{array}{c}\text { Total } \\
\text { (N=331) }\end{array}$ & $\begin{array}{c}\text { Selected } \\
(\mathbf{N}=\mathbf{2 1 7})\end{array}$ \\
\hline Agriculture, forestry and logging & $11 \%$ & $10 \%$ \\
\hline Processing industry & $49 \%$ & $48 \%$ \\
\hline Electricity, gas and construction & $12 \%$ & $14 \%$ \\
\hline Transport, commerce and hospitality & $16 \%$ & $15 \%$ \\
\hline Office work, informatics, education, culture and research & $12 \%$ & $13 \%$ \\
\hline Total & $100 \%$ & $100 \%$ \\
\hline Size expressed as the number of employees & & \\
\hline Small organizations (up to 99) & $50 \%$ & $54 \%$ \\
\hline Medium-sized organizations (100-249) & $32 \%$ & $32 \%$ \\
\hline Large organizations (250 or more) & $18 \%$ & $14 \%$ \\
\hline Total & $100 \%$ & $100 \%$ \\
\hline Size expressed as the amount of turnover & & \\
\hline Small organizations (up to CZK 249.9 million) & $25 \%$ & $30 \%$ \\
\hline Medium-sized organizations (CZK 250 million-999.9 million) & $44 \%$ & $46 \%$ \\
\hline Large organizations (CZK 1,000 million or more) & $31 \%$ & $24 \%$ \\
\hline Total & $100 \%$ & $100 \%$ \\
\hline
\end{tabular}

Source: INESAN, proprietary research

\section{Table 1: Structure of the sample}

The data was processed using statistical methods of data analysis based on frequency analysis and second-stage sorting. Statistical hypotheses were tested using the chi-square test of independence (the p value is given), conducted as a standard on a $5 \%$ significance level.

For the analysis, only those respondents were selected who answered the question "How do you measure the degree of meeting objectives set?" other than "By using standardized tools, procedures, or performance metrics". The perception of the lack of information and the difficulty of implementation was identified by the question "When considering the implementation of the performance measurement system, what specific problems would be most important in your organization?". Responders could choose from several options that included "implementing such a system; the organization is not currently ready for it" and "a lack of information to choose the adequate solution".

Performance measurement of selected areas was identified by the question "In which specific areas do you perform a systematic comparison of achieved results with predetermined goals?". Responders could choose from several options (see research question 1.5). Performance measurement procedures were identified by the question "How do you use the performance metrics in your organization?" Responders could choose from several options (see research question 1.5). Performance measurement issues were identified by question "What specific issues are you struggling with in your organization in performance measurement?" Responders could choose from several options (see 1.5 research question). 


\section{Results}

\subsection{Lack of information}

\subsubsection{Performance measurement areas}

Does performance measurement in certain areas influence the perception of having enough information for choosing an adequate PMS? Analysis shows that there is a positive association: if the managers measure the performance of an organization in selected areas, namely finance $(\mathrm{p}=0,000), \operatorname{HRM}(\mathrm{p}=0,002)$ and marketing $(\mathrm{p}=0,002)$, they are less likely to believe they lack the information needed for choosing an adequate system (Fig. 1).

Performance measurement plays an important role in finance, which has the strongest relation to the knowledge of which tool to choose for measurement. The managers of organizations that do not measure financial performance are much more likely not to know which solution to choose $(72 \%)$ than at organizations that measure this issue (29\%).

HRM follows finance, as the managers in organizations where HRM performance is not measured are much less likely to know which solution to choose $(48 \%)$ than at organizations where HRM is measured (27\%). The situation is similar when it comes to marketing, and less so with sales. The relation showed as statistically irrelevant only when measuring the performance of sales $(p=0,064)$ and a strategy and sales $(p=0,145)$, although the absence of difficulties with a lack of information was cited most often by the representatives of organizations who stated that their organizations did not measure corporate strategies (76\%).

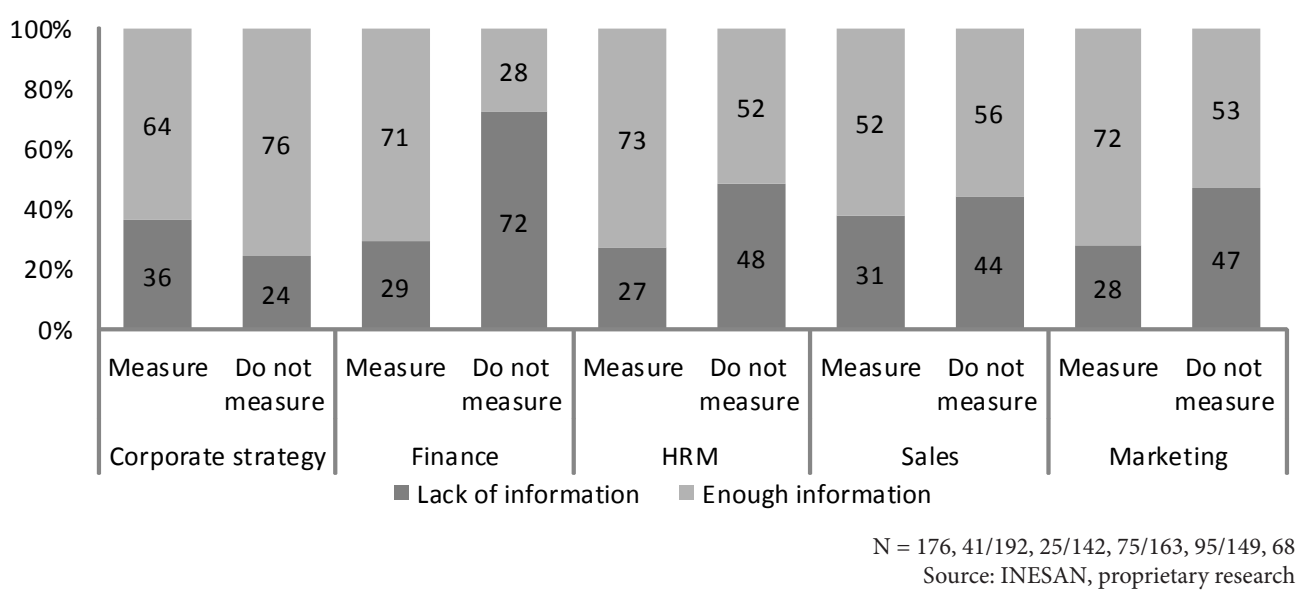

Figure 1: Perception of a lack of information based on performance measurement in selected areas 


\subsubsection{Performance measurement procedures}

It shows that specific procedures are applied in connection with the perception of a lack of information (Fig. 2). The procedures include using performance indicators for the purposes of ongoing monitoring of results $(\mathrm{p}=0,001)$ and obtaining information to rectify deviations from objectives $(\mathrm{p}=0,052)$. The organizations that use performance indicators in this way are less likely to perceive a lack of information about an adequate solution.

From this perspective, the ongoing monitoring of the results is most important. The organizations that apply this procedure are less likely to suffer from problems with the availability of information (24\%) than organizations that do not apply it (47\%). A systematic practice contributes towards the ability to decide which standardized tool to choose. It also shows the specificity of focus on the strategy of the organization where the relationship tends to be reverse, though a statistically relevant relationship has not emerged $(\mathrm{p}=0,117)$. A comparison of the actual results with the expectations or plans yields similar results $(\mathrm{p}=0,064)$.

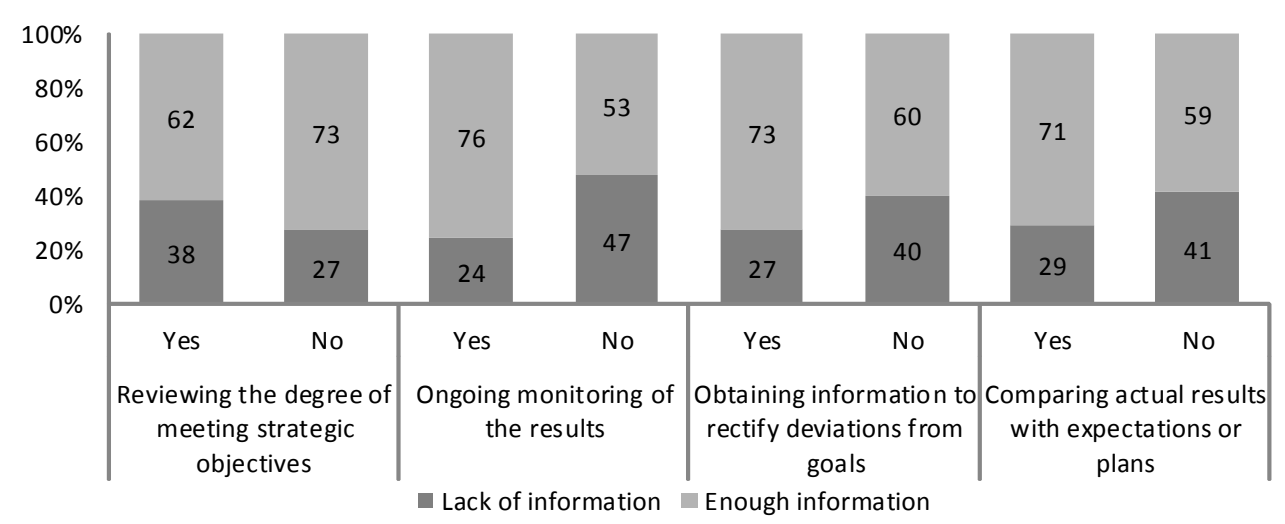

$\mathrm{N}=137,80 / 123,94 / 102,115 / 130,87$

Source: INESAN

Figure 2: Perception of a lack of information depending on the application of performance measurement procedures

Speaking about the application of performance indicators with a view to achieving the values of the individual performance indicators, the relationship did not emerge either (results not shown). 


\subsubsection{Performance measurement issues}

Is the occurrence of selected issues that business organizations encounter in performance measurement in relation to the declared lack of information? In certain cases, an analysis showed a relation - and always a negative one. It is principally the lack of knowledge of how the measurement should be done $(\mathrm{p}=0,000)$ that is very closely related to the fact that the organization's managers lack information to make the decision for an adequate solution: A total of $76 \%$ of the representatives of organizations declaring they do not know how to measure performance claim that they do not have enough information to choose an adequate solution, whereas others accounted for $26 \%$ (Fig. 3).

A lack of interest on the part of the management team accounts for a similar share $(p=0,019)$. A total of $70 \%$ of the representatives of organizations where performance measurement is problematic due to a lack of interest on the part of the management also claim a lack of information. In the opposite case just $34 \%$ of organizations claim a lack of information. Other major factors related to a lack of information include an unclear understanding of user expectations $(0,000)$ and an insufficient analysis of business processes $(p=0,012)$.

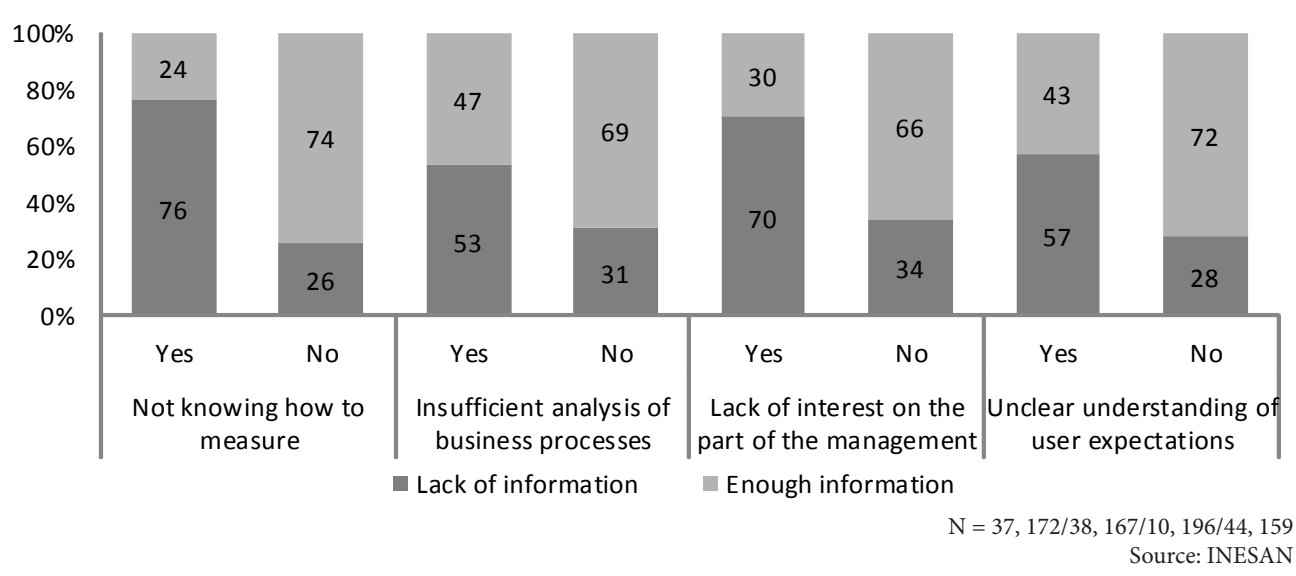

Figure 3: Relation between the perception of a lack of information and topical problems in performance measurement

Concerning issues such as corporate culture not fostering performance measurement, low analytical abilities of in-house personnel, insufficient cooperation between various department or teams, and a lack of data, no relation was proven (results not shown). 


\subsection{Difficulty of implementation}

\subsubsection{Performance measurement areas}

Do the representatives of Czech business organizations perceive implementation as difficult depending on whether or not they measure performance in the various areas? Where organizations measure performance as regards the corporate strategy $(p=0,050)$, sales $(p=0,001)$ and marketing $(\mathrm{p}=0,012)$, the perceived difficulty is cited as an obstacle to implementing a PMS more often than when the management does not focus on the area (Fig. 4). This applies especially to the field of sales where the members of the organizations that do not measure sales perceive implementation as an obstacle more often (29\%) than the representatives of organizations where sales are monitored (7\%). The relationship did not prove to be statistically important in the case of finance $(\mathrm{p}=0,136)$ and HRM $(\mathrm{p}=0,096)$.

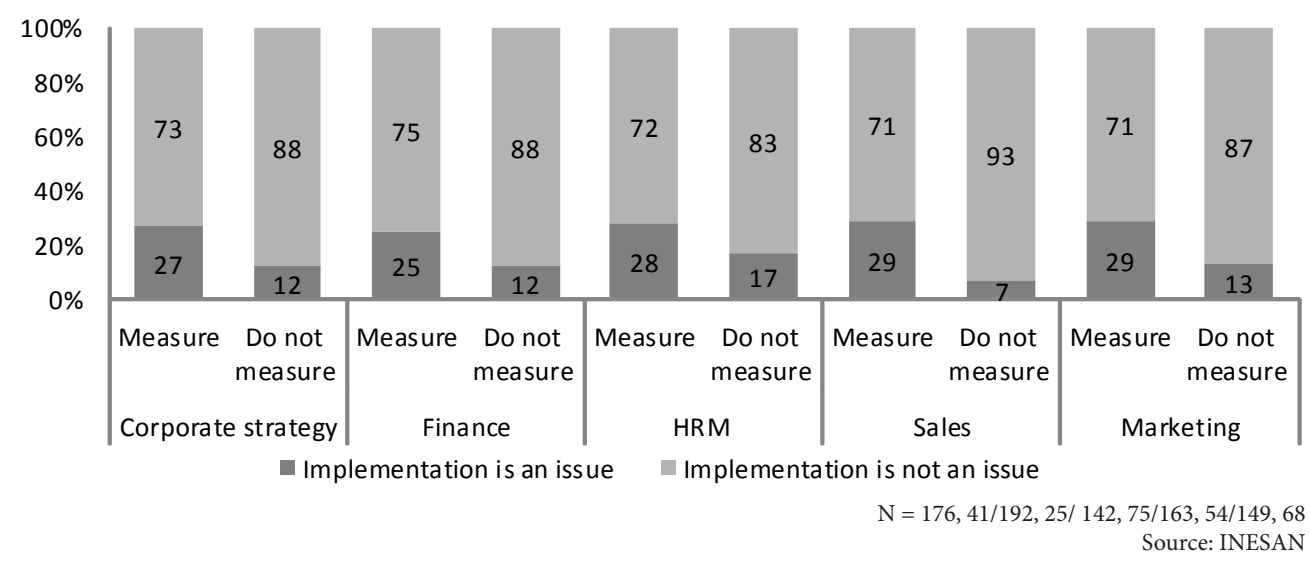

Figure 4: Perception of difficulty of implementation based on performance measurements in selected areas 


\subsubsection{Performance measurement procedures}

Does the perception of difficulty of implementation grow with the application of certain organization performance measurement procedures? Analysis shows that organizations that monitor results on an ongoing basis, compare the actual results with expectations or plans or verify achieving the values of the individual performance indicators more often perceive implementation as difficult (Fig. 5).

This shows most prominently when comparing the actual results with expectations or plans: A total of $32 \%$ of representatives of the entities that follow these procedures and $11 \%$ of the representatives of organizations that do not perceive difficulty of implementation. Also, where organizations monitor results on an ongoing basis, implementation is considered an obstacle more often (32\%) than where results are not monitored (14\%). The situation is very similar where organizations verify achieving the values of the individual performance indicators.

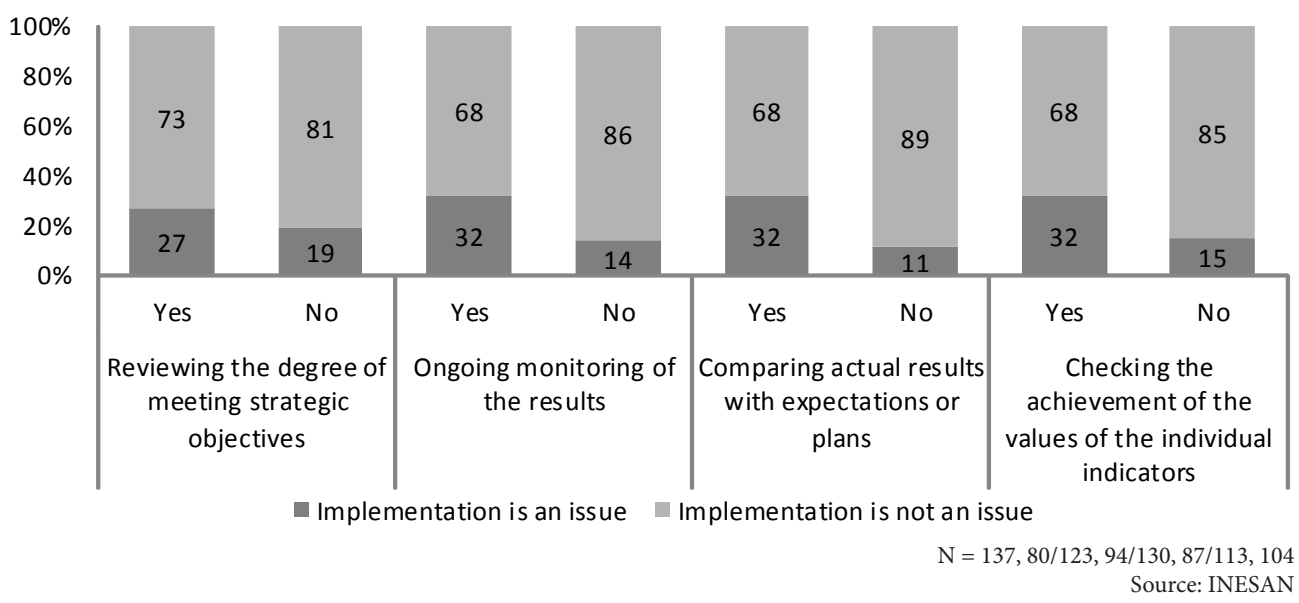

Figure 5: Perception of implementation depending on the application of performance measurement procedures

No relation was demonstrated when it comes to the application of performance indicators for measuring the observance of the strategic goals, and obtaining information to rectify deviations from goals (results of the second and the third not shown). 


\subsubsection{Performance measurement issues}

Is the occurrence of the selected issues that business organizations encounter in performance measurement related to the declared perception of difficulty of implementation? Based on the analysis, the perception of difficulty of implementation is related to insufficient analysis of business processes $(\mathrm{p}=0,027)$, corporate culture not fostering performance measurement $(p=0,000)$, lack of interest on the part of the management $(p=0,007)$ and insufficient cooperation between various departments or teams $(p=0,000)$ (Fig. 6).

Corporate culture not fostering performance measurement is at the forefront: representatives who describe their organizations' culture as such tend to perceive implementation as an issue more often (60\%) than representatives of other organizations (21\%). The situation with a lack of interest on the part of the management is very similar. Insufficient analysis of business processes is less important: representatives who consider this an issue in performance measurement are also more likely to consider implementation an obstacle to the adoption of a PMS (40\%) than those who have no issue with business process analysis. The situation was similar in the case of insufficient cooperation between various departments or teams.

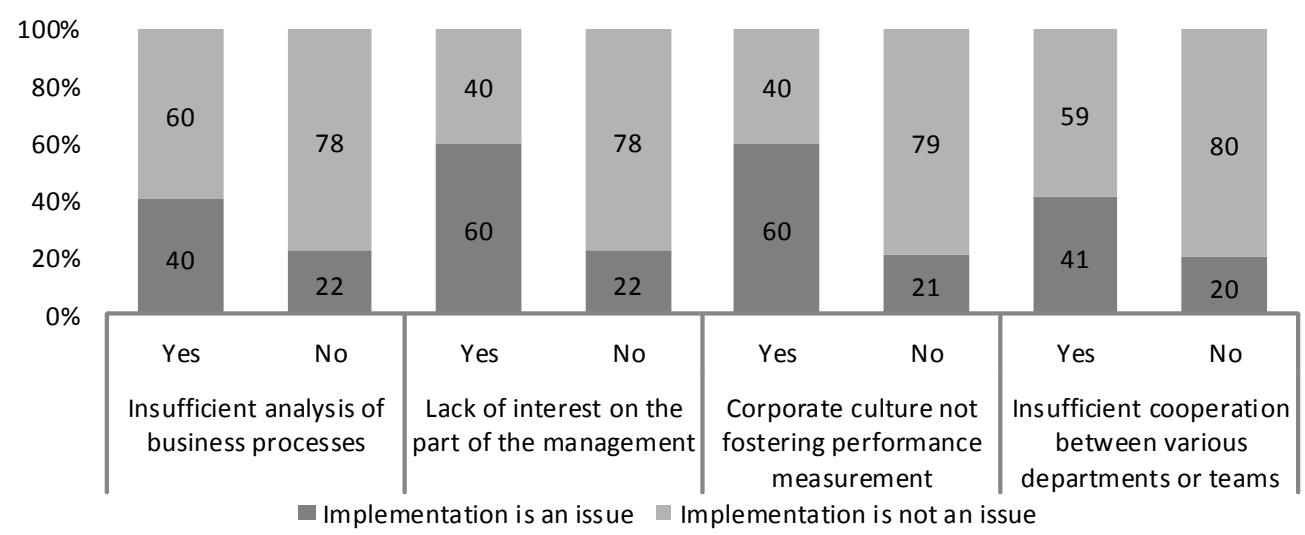

$\mathrm{N}=38,167 / 10,196 / 20,187 / 35,174$ Source: INESAN

Figure 6: Perception of implementation depending on the performance measurement problems encountered

No relation emerged in the case of issues such as a lack of knowledge of how to measure performance, low analytical abilities of in-house personnel, unclear understanding of user expectations, and a lack of data (results not shown).

\subsection{Comparison}

According to the analysis, the measurement in selected areas and the use of selected procedures play different roles considering the perception of a lack of information for choosing an adequate tool and the difficulty of implementation.

Areas of performance measurement (Fig. 1 and 4): Only performance measurement in marketing influences both the perception of a lack of information (if a certain area is measured, the representatives of organizations are less likely to perceive the issue of availability 
of adequate information) and the difficulty of implementation (if a certain area is measured, the representatives of organizations are more likely to perceive difficulty of implementation). Whereas the measurement of finance and HRM plays a major role in terms of a lack of information, the relationship to the measurement of these areas was not confirmed when it comes to implementation being problematic. A comparison of the influence of measurement in marketing, finance and HRM indicates that the measurement in marketing - unlike with the measurement of finance and HRM that does not mean an increase or decrease of uncertainty about the issue of implementation - is related to implementation being problematic more often. Measurement in selected areas has a greater influence on the perception of a lack of information than on the perception of difficulty of implementation.

Procedures of performance measurement (Fig. 2 and 5): Ongoing monitoring of results and comparing of actual results with expectations or plans influences both the lack of information and problematic implementation. By contrast, the measurement of the degree of meeting strategic goals did not prove statistically significant; from the viewpoint of the procedure applied at an organizations, these may be just vague declarations that do not represent the application of certain processes. The application of performance measurement procedures has a greater impact on the perception of the difficulty of implementation than on the perception of a lack of information.

Issues in performance measurement (Fig. 3 and 6): The higher percentage of both analysed obstacles being cited as obstacles to the adoption of a PMS is due to the insufficient analysis of business processes and a lack of interest on the part of the management influence, to an equal degree. Other difficulties in performance measurement are related either to a lack of information or to a difficulty of implementation. As regards the perception of a lack of information, it is the fact that organizations encounter not knowing how to measure performance, and as regards implementation, poor collaboration between various departments and teams plays a role. In all cases, the relationship is that of a positive association where organizations with topical issues in performance measurement cite a lack of information or concerns of implementation more often.

\section{Discussion, limitations and conclusions}

Tangen (2004) focuses on certain problematic aspects that make it impossible to obtain adequate information on performance measurement tools. However, this analysis shows that existing practice is one of the factors that Tangen (2004) does not mention and that is negatively reflected in the absence of information from the representatives of organizations regarding the choice of an adequate solution. The application of specific performance measurement procedures increases the knowledge and information about performance measurement processes, giving an organization a better idea of the issues it will have to address during the process of adopting the tool. The results also point to the importance of the previous practice, which forms the prerequisites for adopting a standardized performance measurement tool. When applying certain performance measurement procedures, the amount of knowledge and information on performance measurement processes is increasing, so choosing from various measurement methods need no longer be difficult for organizations. Out of the selected areas of organization activity, measurement in the field of finance has a particularly strong effect. This is probably the result of the tradition of measuring financial indicators; they are easy to measure, allowing for applying relatively simple PMS (cf. Synek, 2008). 
Although performance measurement in the individual areas of organization activity in general is positively related to the information available to organizations, this is not the case when it comes to the evaluation of the degree of meeting strategic goals or measuring performance in terms of strategy. The reason may be that the operationalization of strategy is identified as one of major problems that organizations tackle in technical literature (e.g., Brocke and Rosemann, 2015). The strategy represents a level from which performance management tools are derived and specified for the individual areas of activity, which may invoke more questions regarding an adequate PMS. According to de Waal and Counet (2009) the area of strategy involves issues of structuring the goals for lower levels, defining success factors and indicators, and linking them to the other units of the organization.

Wouters and Sportel (2005) point out that implementation may contest the strategic assumptions, which could be of importance in the systematic performance measurement in the area of strategy, which may lead to considerations regarding the adequacy of strategy conceptualization more often. As a result, this area of organization activity may not represent the obtaining of the requisite information, instead making the process of adopting the PMS problematic, or being made problematic itself.

As has been said in relation to Tangen (2004), a certain practice has a positive effect on the awareness of adequate PMS. As regards implementation, theorists assert that the issue of management culture is crucial for managing organizations in general and for implementation processes in particular (Boyce et al., 2015; Tangen, 2004; Basuony, 2014), as it also involves the issue of performance management level. The analysis presented here indicates that when it comes to the perception of both a lack of information and problematic implementation, ongoing monitoring of results and comparing of the actual results with the expectations or plans - i.e. systematic and specific practice - has an influence. Aside from the aforementioned notion that the management using a higher level of management practice or organization performance is a prerequisite for successful implementation, it would be possible to formulate another notion to the effect that the management may also be more concerned about the implementation. This shows the importance of previous practice, which contributes towards the creation of an idea of the implementation process and its problematization.

Tangen (2004) believes the decision making at organizations is made difficult by the inability to choose the indicators (or concepts) from an extensive offer, which could be used successfully in practice. This survey also points to the relation between not knowing how to measure performance and the perception of a lack of information about an adequate tool.

The perception of difficulty of implementation is related to insufficient analysis of business processes. This is in line with Tangen's opinion (2004), which includes insufficient analysis of the in-house environment as a source of key and specific indicators in the principal problems that organizations tackle when obtaining information about adequate performance measurement tools. The finding also supports the idea of Garengo et al. (2005) pointing out the problem of deformation of the PMS model and elimination of some of its dimensions on the basis of insufficient analysis of the company's characteristics.

De Waal and Counet (2009) as well as Cavalluzzo and Ittner (2004) note the absence of sufficient amount of interest on the part of the management when it comes to implementation. This shows that if an organization is characterized by a lack of interest on the part of the management and a corporate culture not fostering performance measurement, it tends to consider implementation an issue precluding the adoption of the PMS more often. 
As regards implementation, this analysis shows that another key factor is the insufficient cooperation between various departments and teams. This is a factor that is often omitted, although the alignment of processes within an organization should be part of strategic management, which is part of performance management and whose absence affects the implementation (cf. Boyce et al., 2015; Tangen, 2004; Basuony, 2014).

The existing practice in measuring the performance in the various areas increases the awareness of the possible methods of measurement using standardized tools. Strategy is an exception to this rule. The analysis also shows that the measurement of financial performance may be the principal factor for choosing a standardized tool whereas the other areas, which do not provide such clear guidance, may play the role of a problematic addition.

The results of the analysis show that the previous practice is important as a prerequisite for the adoption of a standardized PMS and also as a source of doubt as to the success of the implementation. If an organization's management does not monitor performance in certain areas (in particular in finance, HRM and marketing), it lacks experience with certain performance measurement procedures (using performance indicators for ongoing monitoring of the results, obtaining information to rectify deviations from objectives and for comparing actual results with expectations or plans) and encounters certain problems in performance measurements (not knowing how to measure, insufficient analysis of business processes, lack of interest on the part of the management and unclear user expectations), and it also perceives the lack of information for choosing an adequate PMS as problematic more often.

Furthermore, if the management of an organization monitors performance in certain areas (except for finance and HRM), it applies certain performance measurement procedures (ongoing monitoring of the results, comparing actual results with expectations or plans and checking the achievement of the individual performance indicator values), or it encounters certain problems in performance measurement (insufficient analysis of business processes, corporate culture not fostering performance management, lack of interest on the part of the management and low analytical skills of in-house staff), and it also perceives implementation as problematic more often.

Based on the analysis of measurement in selected areas and using selected procedures (in particular the monitoring of finance, ongoing monitoring of the results and comparing the actual results with expectations or plans) plays a different role as regards the perception of a lack of information and difficulty of implementation. While, on the one hand, these practices reduce the ignorance and inability to choose an adequate tool, on the other hand they increase the degree of perception of difficulty of implementation, if any. By contrast, issues of performance measurement positively correspond with both issues analysed.

Finally, it can be pointed out that if the management focuses on continuous measurement in certain areas (marketing, finance, HRM), takes care of the analysis business processes, and fosters co-operation between workplaces, it facilitates the process of choosing an adequate solution for measurement. At the same time the management should strengthen its awareness of the implementation steps of the performance measurement system.

The limitation as regards the conclusions of this paper stems from the fact that they are drawn on the basis of data collected in 2012. Since these are the latest available data and there is a shortage of data on the matter in this field of research, the author deemed it fitting to use these data as well. Claims regarding the current situation would require the collection of new data and a verification of any changes that occurred in the meantime. It is also necessary 
to point out the fact that the data reflect the situation of developed economic crisis, which started to affect the Czech Republic strongly from 2009. Economic instability combined with concerns about the future development can have a profound effect on the thinking of the managers of corporations as regards the innovations in performance measurement. Hence, there may have been a shift in the perception of the necessity of adopting a measurement system, which tends to be a long-term tool, and a more intensive perception of barriers than during the period of economic crisis.

The insights obtained are basic, and a deeper understanding of the matter would require a more analytical focus on the individual problems as part of the defined areas of the process of adoption of performance measurement tools. Attention could be focused on how the representatives of organizations perceive the supply of the solutions offered at the time and their attractiveness, usability and availability. The implementation process per se represents a set of many individual problems, as part of which further individual barriers and issues may be identified on various levels (technical, organizational and HR).

\section{References}

Bastian, B., Muchlish, M., 2012. Perceived Environment Uncertainty, Business Strategy, Performance Measurement Systems and Organizational Performance. Procedia - Social and Behavioral Sciences, 65. 787-792. ISSN 1877-0428.

Basuony, M. A. K., 2014. The Balanced Scorecard in Large Firms and SMEs: A Critique of the Nature, Value and Application. Accounting and Finance Research, 3, 2. 14-22. ISSN 1927-5986.

Beaver, G., 2002. Strategy and Management in the Smaller Enterprize [online]. Strategic Change, 11, 4, 175-181 [Retrieved 26.9.2017]. ISSN 1099-1697. Available from: http://onlinelibrary.wiley.com/ doi/10.1002/jsc.591/abstract?userIzauthenticated=false\&deniedAccessCustomizedMessage $=$.

Bourne, M., Neely, A., Mills, J., Platts, K., 2003. Implementing Performance Measurement Systems: A Literature Review. International Journal of Business Performance Management, 5, 1. 1-24. ISSN 1368-4892.

Boyce, A. S., Nieminen, L. R. G., Gillespie, M. A., Ryan, A. M., Denison, D. R., 2015. Which Comes First, Organizational Culture or Performance? A Longitudinal Study of Causal Priority with Automobile Dealerships. Journal of Organizational Behaviour 36, 3. 339-359. ISSN 1099-1379.

Brocke, J. vom, Rosemann, M., 2015. Handbook Business Process Management 2. Strategic Alignment, Governance, People and Culture. 2nd. Springer-Verlag Berlin Heidelberg. XVII, 865 p.

ISBN 978-3-642-45102-7.

Cavalluzzo, K. S., Ittner, Ch. D., 2004. Implementing Performance Measurement Innovations: Evidence from Government. Accounting, Organizations and Society, 29, 3-4. 243-267. ISSN 0361-3682.

Chubb, C., Reilly, P., Brown, D., 2011. Performance Management. Literature Review. IES HR Network [Retrieved 22.1.2018]. Available from: http://www.employment-studies.co.uk/system/files/resources/ files/mp90.pdf.

Daňková, J., 2014. Inovační vouchery pomohly ke vzniku nové metody předpovídání výkonnosti malých a středních podniků [on-line]. Press release. Prague: University of Economics in Prague, 14. 7. 2014 [Retrieved 26.9.2017]. Available from: https://www.vse.cz/media/tiskove-zpravy.php?rok=2014.

De Waal, A. A., Counet, H., 2009. Lessons Learned from Performance Management Systems Implementations. International Journal of Productivity and Performance Management, 58, 4. 367-390. ISSN 1741-0401.

De Waal, A. A., Kourtit, K., 2013. Performance measurement and management in practice. 
International Journal of Productivity and Performance Management, 62, 5. 446-473.

ISSN 1741-0401.

Eckerson, W. W., 2010. Performance Dashboards: Measuring, Monitoring, and Managing Your Business. Wiley. 336 p. ISBN 978-0470589830.

Fernandes, K. J., Raja, V., Whalley, A., 2006. Lessons from Implementing the Balanced Scorecard in a Small and Medium Size Manufacturing Organization. Technovation, 26, 5-6. 623-634. ISSN 0166-4972.

Garengo, P., Biazzo, S., Bititci, U. S., 2005. Performance Measurement Systems in SMEs: A Review for a Research Agenda. International Journal of Management Reviews, 7, 1. 25-47. ISSN 1468-2370.

Gimžauskienė, E., Varaniūte, V., 2012. Impact of Information and Communication Technology for Funcionality of Performance Measurement system. Economics and Management, 17, 1. 15-21. ISSN 2029-9338.

Gruntová Kolingerová, H., 2016. Překážky přijetí systému hodnocení výkonnosti organizace [online]. Ekonomika a management, issue 4 [cit.26.9.2017]. ISSN 1802-8934. Available from:

https://www.vse.cz/eam/284. ISSN 1802-8934.

Henri, J.-F., 2006. Organizational Culture and Performance Measurement Systems. Accounting, Organizations and Society, 31. 77-103. ISSN 0361-3682.

Hoque, Z., 2014. 20 Years of Studies on the Balanced Scorecard: Trends, Accomplishments, Gaps and Opportunities for Future Research. The British Accounting Review, 46, 1, March. 33-59. ISSN 0890-8389.

Keathley, H., 2017. An Approach to Quantify the Factors That Affect Performance Measurement System Implementation. Engineering Management Journal, 29, 2. 63-73. ISSN 1042-9247.

Keathley, H., Van Aken, E., 2013. Systematic Literature Review on the Factors that Affect Performance Measurement System Implementation. Conference paper. In: Krishnamurthy, A. (ed.), 2013. 63rd Annual Conference and Expo of the Institute of Industrial Engineers 2013, Proceedings of a meeting held 18-22 May 2013, San Juan, Puerto Rico. Institute of Industrial Engineers, Annual Conference. 837-846. ISBN 9781632663085.

Lönnqvist, A., 2004. Measurement of Intangible Success Factors: Case Studies on the Design, Implementation and Use of Measures. Tampere: Tampere University of Technology. 255 p. ISBN 952-15-1183-4.

Marr, B., 2009. Managing and Delivering Performance. Oxford, Butterworth-Heinemann. 295 p. ISBN 978-0750687102.

Monkhouse, E., 1995. The Role of Competitive Benchmarking in Small to Medium-Sized Enterprizes. Benchmarking for Quality Management and Technology, 2, 4. 41-50. ISSN 1351-3036.

Muscalu, E., Şerban, A., 2014. HR Analytics for Strategic Human Resource Management. Proceedings of the International Management Conference, 8, 1. 939.

Ochurub, M., Bussin, M., Goosen, X., 2012. Organizational Readiness for Introducing a Performance Management System. SA Journal of Human Resource Management, 10, 1. 11. ISSN 1683-7584.

Paranjape, B., Rossiter, M., Pantano, V., 2006. Performance Measurement Systems: Successes, Failures and Future - a Review. Measuring Business Excellence, 10, 3. 4-14. ISSN 1368-3047.

Roshan, D., Jenson, J. E., 2014. Study on Performance Measurement Systems - Measures and Metrics. International Journal of Scientific and Research Publications, 4, 9, September. 1-10. ISSN 2250-3153.

Synek, M., 2008. Nová ekonomika, nové ukazatele. Ekonomika a management [online], 2 [cit.26.9.2017]. ISSN 1802-8934. Available from: http://www.ekonomikaamanagement.cz/cz/claneknova-ekonomika-nove-ukazatele.html.

Spearman, K., 2007. Financial Management for Local Government. Routledge. 1670 p. ISBN 9781136565816.

Tangen, S., 2004. Evaluation and Revision of Performance Measurement Systems. Doctoral thesis. Department of Production Engineering, Royal Institute of Technology, Stockholm, Sweden. 193 p. ISBN 9172838604. 
Todorov, K., Smallbone, D., 2014. Handbook of Research on Strategic Management in Small and Medium Enterprizes. IGI Global. 508 s. ISBN 9781466659636.

Ulf, J., Matti, S., Andreas, B., Roland, A., 2006. Balancing Dilemmas of the Balanced Scorecard. Accounting, Auditing \& Accountability Journal, 19, 6. 842-857. ISSN 0951-3574.

Vincent, C; Kumar, M. 2014. Business Performance Measurement and Management. Newcastle upon Tyne: Cambridge Scholars Publishing, 2014. ISBN 9781443861397.

Wouters, M., Sportel, M., 2005. The Role of Existing Measures in Developing and Implementing Performance Measurement Systems. International Journal of Operations \& Production Management, 25, 11. 1062-1082. ISSN 0144-3577.

The article presents the findings of the research carried out under project No. CZ.3.01.2012.221.002 entitled Performance Measurement Systems in the Czech Organisations, solved by The Institute for Evaluations and Social Analyses (INESAN).

Hana Gruntová Kolingerová hana.gruntova@inesan.eu

Department of Management Studies, Institute for Evaluations and Social Analyses 